\title{
Optimization of an Existing Coal-fired Power Plant with $\mathrm{CO}_{2}$ Capture
}

\author{
Ying Wu, Wenyi Liu, Yong-ping Yang \\ School of Energy Power and Mechanical Engineering, North China Electric Power University, Beijing, China \\ Email: 837469236@qq.com; xgncepu@163.com
}

Received February, 2013

\begin{abstract}
Nowadays, the worsening environmental issue caused by $\mathrm{CO}_{2}$ emission is greatly aggravated by human activity. Many $\mathrm{CO}_{2}$ reduction technologies are under fast development. Among these, monoethanolamine (MEA) based $\mathrm{CO}_{2}$ capture technology has been paid great attention. However, when connecting the $\mathrm{CO}_{2}$ capture process with a coal-fired power plant, the huge energy and efficiency penalty caused by $\mathrm{CO}_{2}$ capture has become a serious problem for its application. Thus, it is of great significance to reduce the related energy consumption. Based on an existing coal-fired power plant, this paper proposes a new way for the decarburized retrofitting of the coal-fired power plant, which helps to improve the overall efficiency of the power plant with less energy and efficiency penalty. The decarburized retrofitting scheme proposed will provide a new route for the $\mathrm{CO}_{2}$ capture process in China.
\end{abstract}

Keywords: MEA; $\mathrm{CO}_{2}$ Capture; Decarburized Retrofitting; Coal-fired Power Plant

\section{Introduction}

The increased $\mathrm{CO}_{2}$ emission has led to great concern of people when confronted with today's environmental phenomena such as global warming and rising sea levels [1]. China, one of the world's largest producers of $\mathrm{CO}_{2}$, is responsible for approximately one-fifth of the world's $\mathrm{CO}_{2}$ emissions and $\mathrm{CO}_{2}$ emitted from coal-fired power plants accounts for nearly $50 \%$ of the total $\mathrm{CO}_{2}$ emission. The $\mathrm{CO}_{2}$ capture and storage (CCS) technology, especially the monoethanolamine (MEA) based $\mathrm{CO}_{2}$ capture method is commonly considered as a feasible option for $\mathrm{CO}_{2}$ reduction[2-3].

However, when connecting $\mathrm{CO}_{2}$ capture with an existing coal-fired power plant, the huge energy consumption for the $\mathrm{CO}_{2}$ capture process will dramatically reduce overall efficiency of the power plant, which becomes a technical barrier for its fast development [4]. Thus, how to minimize the related energy consumption is of great significance for $\mathrm{CO}_{2}$ capture application[5].

Based on an existing coal-fired power plant, a new decarburized retrofitting scheme is proposed by fully utilizing the surplus energy instead of abandoning it, which provides a new route for the $\mathrm{CO}_{2}$ capture application in the thermal power plants.

\section{Selected Reference System of the Power Plant and Capture Process}

\subsection{A Typical 350 MW Coal-fired Power Plant in China}

The schematic of a typical coal-fired power plant with
350 MW output is selected as the reference system, which is given in Figure 1.

As shown in the figure, for the steam/water cycle, the turbines consist of high pressure (HP), intermediate pressure (IP), and low pressure (LP) turbines connected to the generator with a common shaft. Steam from the exhaust of the HP turbine is returned to the boiler for reheating and then sent to the IP turbine. Exhaust steam from the IP turbine passes through the one-cylinder/ double-exhaust LP turbines and flows into the condenser. Before recycling back to the boiler, the condensed water will be heated in the high-pressure and low-pressure regenerative heaters, in which the thermal heat is supplied by steam extraction from different turbine cylinders.

For the exhaust flue gas, after leaving selective catalytic reduction (SCR), electrostatic precipitator (ESP) and flue gas desulphurization (FGD) to get rid of some toxic gases like $\mathrm{NO}_{\mathrm{x}}$ and $\mathrm{SO}_{2}$, the flue gas will pass through the $\mathrm{CO}_{2}$ recovery process, in which about $90 \%$ of $\mathrm{CO}_{2}$ will be absorbed. The treated gas, mostly containing $\mathrm{N}_{2}, \mathrm{O}_{2}$ and $\mathrm{H}_{2} \mathrm{O}$, will be directly vented to the atmosphere.

\subsection{MEA-based $\mathrm{CO}_{2}$ Capture Process}

MEA is selected as the absorbent of $\mathrm{CO}_{2}$ capture process since it has various advantages like stability, fast reaction rate and large recovery capacity. MEA-based $\mathrm{CO}_{2}$ capture process, as one of post-combustion $\mathrm{CO}_{2}$ capture processes, is located between the FGD unit and the flue stack, which is a comparatively mature technology and 
has a bright future to be utilized on a large scale. The MEA-based $\mathrm{CO}_{2}$ capture process is shown in Figure 2.

From Figure 2, the MEA-based $\mathrm{CO}_{2}$ capture process can be summarized as follows: (1) The flue gas is compressed by a booster fan; (2) The $\mathrm{CO}_{2}$ in the flue gas is absorbed by MEA in an absorber and the treated flue gas will be directly vented to the atmosphere; (3) The rich amine solution with $\mathrm{CO}_{2}$ is delivered to a heat exchanger by a pump; (4) The rich amine solution will release $\mathrm{CO}_{2}$ and lean ammonia solution in the stripper by reboiler operation; (5) The high-purity $\mathrm{CO}_{2}$ will be flashed in a $\mathrm{CO}_{2}$ cooler, and later compressed and cooled for transport and storage; (6) Contrary to the rich amine solution, the lean ammonia solution leaving from the stripper will release energy in the heat exchanger and be recycled back to the absorber. (7) The makeup MEA solution is also added into the absorber. The main parameter of the MEA-based $\mathrm{CO}_{2}$ capture process is shown in Table 1.

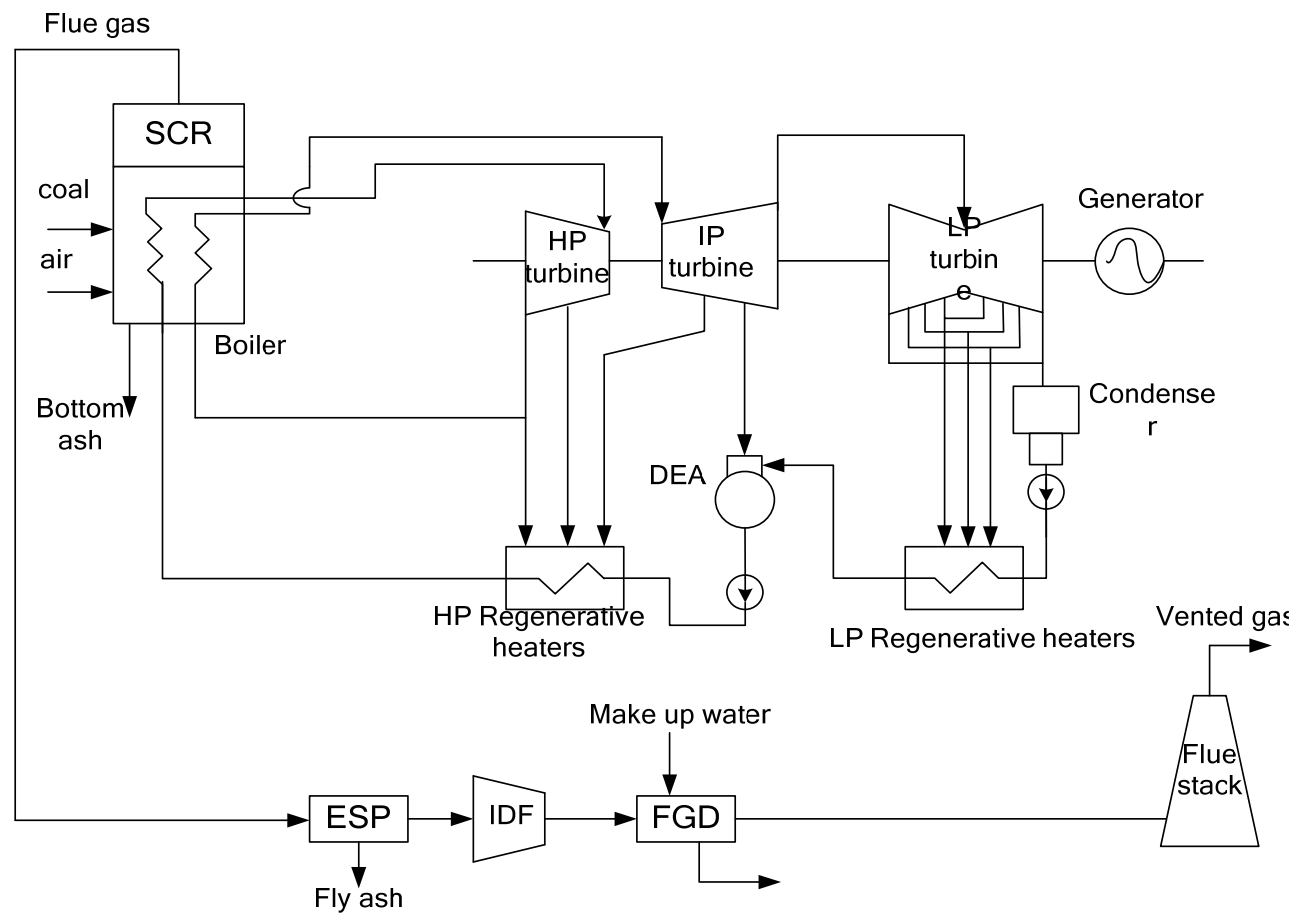

Figure 1. A typical $1000 \mathrm{MW}$ coal-fired power plant in China.

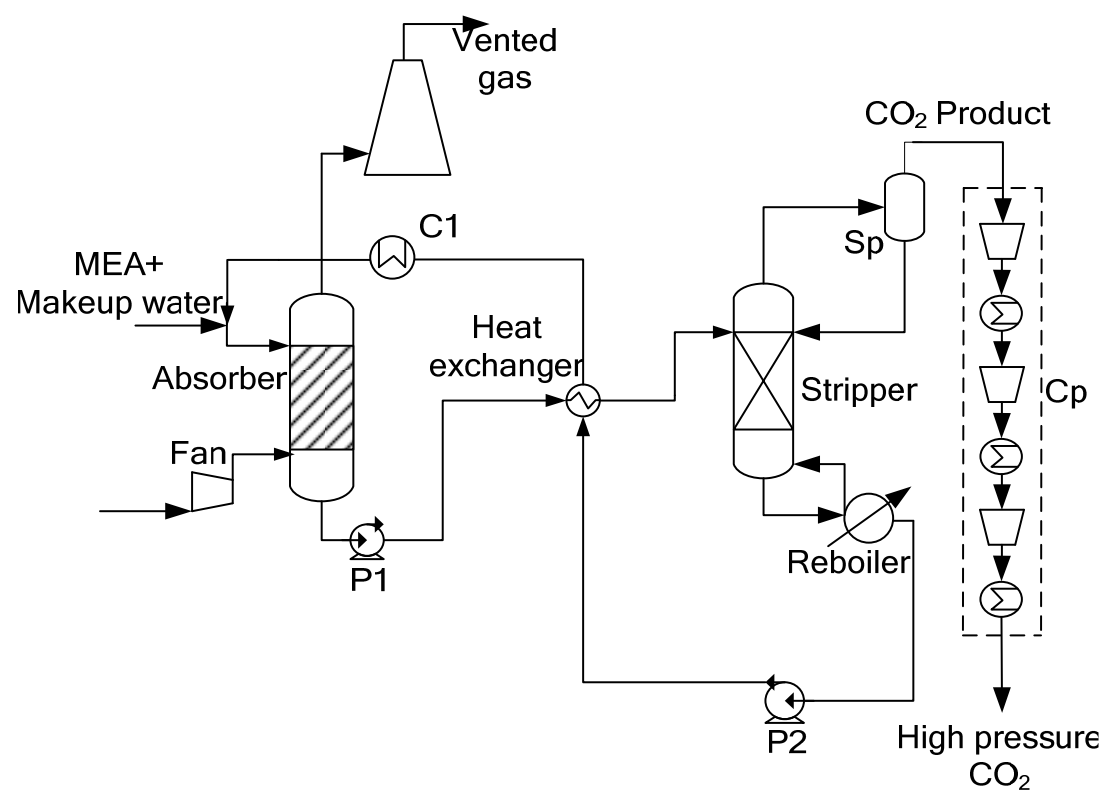

Figure 2. MEA-based $\mathrm{CO} 2$ capture process. 
Usually, the energy for the reboiler duty, with 3.4 $\mathrm{MJ} / \mathrm{kg} \mathrm{CO}$, is provided by the steam extraction from the power generation unit, which leads to great energy and efficiency penalty of the power plant.

\section{The Decarburized Retrofitting of the Coal-fired Power Plant}

\subsection{Scheme 1: The Conventional Decarburized Retrofitting}

The conventional decarburized retrofitting of the coalfired power plant is given in Figure 3. When 90\% of $\mathrm{CO}_{2}$ in the flue gas is separated, the steam extraction for $\mathrm{CO}_{2}$ capture process may account for over half of the total steam flow with pressure of 2bar-4bar. Due to the structural constraints of the LP turbine, it is impossible to extract so much steam within the LP turbine. Thus, the cross pipe between IP turbine and LP turbine is the only feasible extraction point to provide so much steam extraction. The average temperature for the regeneration of MEA absorbent is about $115^{\circ} \mathrm{C}$. In practice, the highest temperature of the extracted steam for absorbent regeneration should not exceed $140^{\circ} \mathrm{C}$. Otherwise, MEA degradation and corrosion issue will be sharply aggravated. Unfortunately, the steam parameter in the extraction point is usually higher than needed. Thus, the extracted steam needs to be throttled and cooled to a suitable pressure and temperature by a couple of throttling valve and cooling equipment. The exhausted water out of the reboiler is recycled back into the condenser.

Table 1. Main parameters of the MEA-based $\mathrm{CO}_{2}$ capture process.

\begin{tabular}{ll}
\hline Item & Value \\
\hline Stripper pressure (bar) & 2.1 \\
Average temperature of reboiler $\left({ }^{\circ} \mathrm{C}\right)$ & 115 \\
$\mathrm{CO}_{2}$ recovery ratio $(\%)$ & 90 \\
$\mathrm{CO}_{2}$ lean loading (molCO$/$ molMEA) & 0.3 \\
$\mathrm{CO}_{2}$ rich loading (molCO$\left./ \mathrm{molMEA}\right)$ & 0.45 \\
Energy consumption of reboiler $\left(\mathrm{MJ} / \mathrm{kg} \mathrm{CO}_{2}\right)$ & 3.4 \\
$\mathrm{Mass}$ purity of separated $\mathrm{CO}_{2}(\%)$ & 99.8 \\
Mole purity of separated $\mathrm{CO}_{2}(\%)$ & 99.6 \\
\hline
\end{tabular}

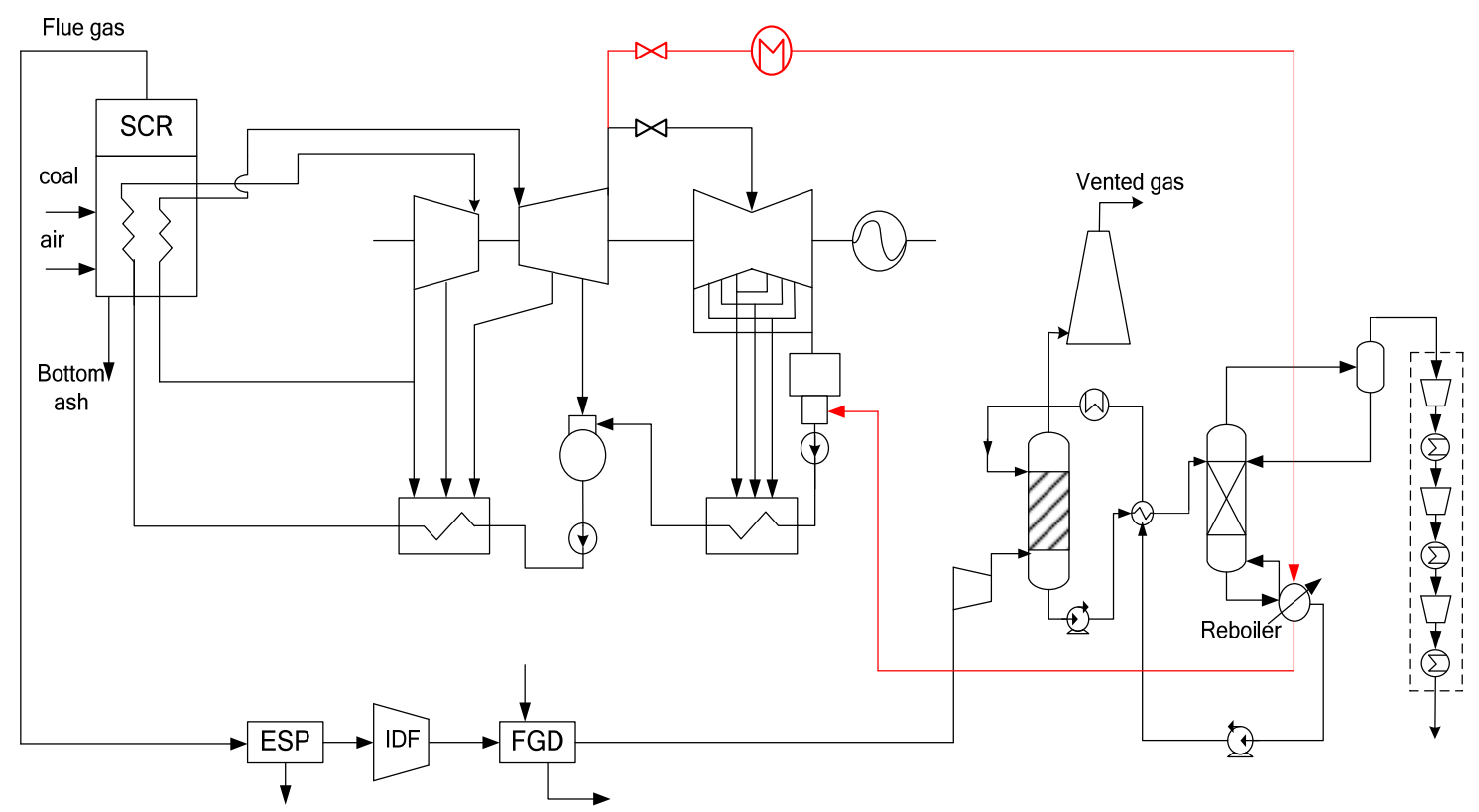

Figure 3. The original decarburized retrofitting scheme of the coal-fired power plant. 


\subsection{Scheme 2: Optimization of the Decarburized Retrofitting}

The decarburized system in Section 3.1 realizes the $\mathrm{CO}_{2}$ capture in cost of great energy consumption. Suppose the surplus energy in the extracted steam can be utilized, it will be certain to improve the thermal performance of the decarburized system.

Thus, to recover the surplus pressure of the extracted steam, a new letdown steam turbine generator (LSTG) is installed to recover the surplus energy of the extracted steam in the new decarburized system, as shown in Figure 4. Such improvement is really simple and easy to implement while it is very effective to retrieve the surplus pressure and temperature, which can also make the output power greatly increase to a certain degree.

\subsection{Performance Evaluation of the Two Capture Systems}

Performance evaluation of the two capture systems is conducted in Table 2.

It is easy to find that, with the help of new LSTG, the net power generation is increased from 211.25 MW to 230.36 MW. The efficiency of the new decarburized sys- tem has increased to $28.01 \%$ with $12.03 \%$ efficiency penalty compared to $14.35 \%$ of the original decarburized system. Thus, the energy-saving effects in the steam extraction point are obvious.

\section{Techno-economic Analysis of the Two Capture Systems}

Techno-economic analysis of the original power plant and two retrofitting schemes is conducted in Table 3.

As shown in the table, the total plant investment of reference system (230.52 $\mathrm{M} \$$ ) are estimated according to the related data of typical $350 \mathrm{MW}$ coal-fired power plants in China with specific plant investment of approximately $700 \$ / \mathrm{kW}$. The total investment of $\mathrm{CO}_{2}$ capture process, estimated based on some demonstration plant in China, reaches 92.15 M\$. Due to the connection with the $\mathrm{CO}_{2}$ capture process, the total plant investment of scheme 1 has reached up to $322.67 \mathrm{M} \$$ with specific plant investment of $1527.43 \$ / \mathrm{kW}$. For scheme 2, although the total plant investment is further increased to 324.27 M\$ with consideration of the added LSTG and the related retrofitting cost, its specific plant investment is reduced to $1407.67 \$ / \mathrm{kW}$ because of the increased net power generation.

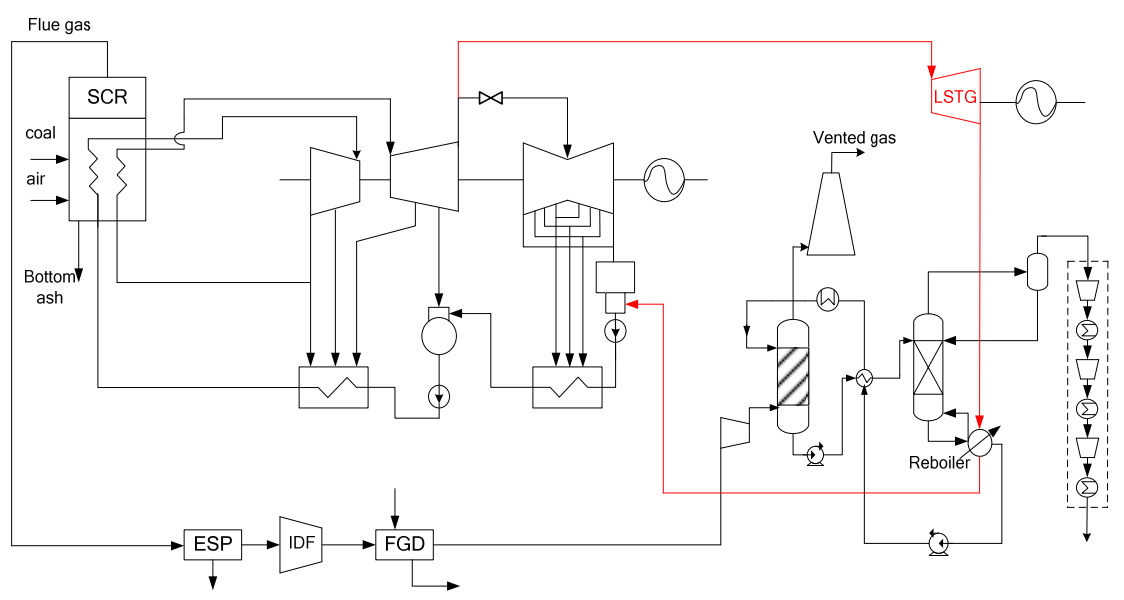

Figure 4. The new decarburized retrofitting scheme of the coal-fired power plant.

Table 2. Overall performance of two capture system.

\begin{tabular}{lll}
\hline Item & Original & New \\
\hline HP, IP \& LP power output (MW) & 260.37 & 260.37 \\
LSTG power output (\%) & - & 19.11 \\
Gross power output (MW) & 260.37 & 279.48 \\
Internal power consumption (MW) & 17.33 & 17.33 \\
Power for $\mathrm{CO}_{2}$ capture process (MW) & 31.79 & 31.79 \\
Net power generation (MW) & 211.25 & 230.36 \\
Total energy of coal input (LHV) & 822.39 & 822.39 \\
Net plant efficiency (\%) & $25.69 \%$ & $28.01 \%$ \\
Original plant efficiency (\%) & $40.04 \%$ & $40.04 \%$ \\
Efficiency penalty (\%) & $14.35 \%$ & $12.03 \%$ \\
\hline
\end{tabular}


Table 3. Techno-economic analysis results.

\begin{tabular}{llll}
\hline Item & Reference & Scheme 1 & Scheme 2 \\
\hline Net plant efficiency (\%) & $40.04 \%$ & $25.69 \%$ & $28.01 \%$ \\
Net power generation (MW) & 329.32 & 211.25 & 230.36 \\
Total plant investment (M\$) & 230.52 & 322.67 & 324.27 \\
Specific plant investment $(\$ / k W)$ & 700.00 & 1527.43 & 1407.67 \\
Cost of electricity $(\mathrm{COE}, \$ / M W h)$ & 57.75 & 103.49 & 94.70 \\
$\mathrm{CO}_{2}$ emission rate $\left(\mathrm{tCO}_{2} / \mathrm{MWh}\right)$ & 0.87 & 0.14 & 0.12 \\
$\mathrm{CO}_{2}$ avoided rate $(\mathrm{tCO} / \mathrm{MWh})$ & 0 & 0.73 & 0.75 \\
$\mathrm{Cost}_{2}$ of $\mathrm{CO}_{2}$ avoided $(\$ / \mathrm{t} \mathrm{CO})$ & 0 & 62.66 & 49.27 \\
\hline
\end{tabular}

For cost of electricity (COE) and cost of $\mathrm{CO}_{2}$ avoided, both of two parameters have the same trend. Their values in scheme 1 are increased when compared to the reference system. However, for scheme 2, due to the increased net power generation, their values are reduced compared to scheme 1 .

To sum up, with the added LSTG, the net efficiency and net electricity generation of the new retrofitting scheme increases while its specific plant investment, $\mathrm{COE}$ and the cost of $\mathrm{CO}_{2}$ avoided reduces, which reflects the economic advantage of the new retrofitting scheme.

\section{Conclusions}

This paper carries out the decarburized retrofitting study of an existing coal-fired power plant in China. Since the energy consumption of the $\mathrm{CO}_{2}$ capture process is extremely huge, the energy and efficiency penalty caused by $\mathrm{CO}_{2}$ capture process becomes a technical barrier for the large-scale $\mathrm{CO}_{2}$ capture application.

Optimization measures are conducted in the conventional decarburized retrofitting scheme. Based on the conventional scheme, a new LSTG is added to recover the surplus energy existed in the extracted steam. Performance results also show its benefits. The added LSTG helps the improvements of the overall performance of the power plant and provides a new route for the $\mathrm{CO}_{2}$ capture application in coal-fired power plants.

Finally, techno-economic results are also conducted. From the results, it is easy to find that the net efficiency and net electricity generation of the new retrofitting scheme increases while its specific plant investment, $\mathrm{COE}$ and the cost of $\mathrm{CO}_{2}$ avoided reduces, which reflects economic benefits of the new retrofitting scheme.

\section{Acknowledgements}

This study has been supported by the National Key Technology R\&D Program of China (2012BAC24B01), National Nature Science Foundation Project (51006034, 51061130538), the Fundamental Research Funds for the Central Universities (11MG04) and International Science and Technology Cooperation Project (2010DFA 72760609).

\section{REFERENCES}

[1] Working Group III of the Intergovernmental Panel on Climate Change (IPCC), "IPCC Special Report on Carbon Dioxide Capture and Storage,” Cambridge, United Kingdom: Cambridge University Press, U.K., 2005.

[2] China Electricity Council, "The Current Status of Air Pollution Control for Coal-fired Power Plants in China 2009,” China Electric Power Press, Beijing, 2009.

[3] Intergovernmental Panel on Climate Change (IPCC) Climate Change 2001: Mitigation, Cambridge: Cambridge University Press, U.K., 2001.

[4] Energy Information Administration, "International Energy Outlook 2009,” DOE/EIA-0484, 2009.

[5] Updated Capital Cost Estimates for Electricity Generation Plants 2010, U.S. Energy Information Administration. 